\title{
Overall skin tone and skin-lightening-improving effects with oral supplementation of lutein and zeaxanthin isomers: a double-blind, placebo-controlled clinical trial
}

Clinical, Cosmetic and Investigational Dermatology

7 October 2016

Number of times this article has been viewed

Vijaya Juturu'

James $\mathrm{P}$ Bowman ${ }^{2}$

Jayant Deshpande'

'Department of Scientific and Clinical Affairs, OmniActive Health Technologies Inc., Morristown, NJ, 2James $P$ Bowman \& Associates LLC, Loveland, OH, USA
Correspondence: Vijaya Juturu Department of Scientific and Clinical Affairs (Global), OmniActive Health Technologies Inc., Morristown, NJ 07950, USA

Email v.juturu@omniactives.com
Purpose: Carotenoids, especially lutein and zeaxanthin isomers ( $\mathrm{L} / \mathrm{Zi})$, filter blue light and protect skin from environmental factors including high-energy sources. These carotenoids may be able to block the formation of melanin pathways, decrease cytokines, and increase antioxidants. Subjects and methods: This is a randomized, double-blind, placebo-controlled clinical trial over a 12-week supplementation period. Fifty healthy people (50 healthy subjects were recruited and 46 subjects completed the study) (males and females, age: 18-45 years) with mild-to-moderate dry skin were included in this study. Skin type of the subjects was classified as Fitzpatrick skin type II-IV scale. Subjects were administered with either an oral dietary supplement containing $10 \mathrm{mg}$ lutein (L) and $2 \mathrm{mg}$ zeaxanthin isomers $(\mathrm{Zi})(\mathrm{L} / \mathrm{Zi}$ : $R R$-zeaxanthin and $R S$ (meso)-zeaxanthin) or a placebo daily for 12 weeks. The minimal erythemal dose and skin lightening $\left(\mathrm{L}^{*}\right)$ were measured via the Chromameter ${ }^{\circledR}$. The individual typological angle was calculated. Subjective assessments were also recorded.

Results: Overall skin tone was significantly improved in the $\mathrm{L} / \mathrm{Zi}$ group compared to placebo $(P<0.0237)$, and luminance $\left(\mathrm{L}^{*}\right)$ values were significantly increased in the $\mathrm{L} / \mathrm{Zi}$ group. Mean minimal erythemal dose was increased with $\mathrm{L} / \mathrm{Zi}$ supplementation after 12 weeks of supplementation. L/Zi supplementation significantly increased the individual typological angle.

Conclusion: L/Zi supplementation lightens and improves skin conditions.

Keywords: lutein, zeaxanthin isomers, skin lightening, minimal erythemal dose, individual typological angle, overall skin tone

\section{Introduction}

Free radicals and imbalance of antioxidant activity ${ }^{1}$ lead to oxidative stress. Breakdown of DNA, lipids, and proteins and pathogenesis of cancer, cardiovascular disease, diabetes, neurodegenerative diseases, and skin aging ${ }^{1,2}$ are caused due to oxidative stress conditions. Dietary antioxidants may protect against oxidative damage and free radical damage due to high-energy sources. Lutein $(\mathrm{L})$ and zeaxanthin $(\mathrm{Z})$ are two of the most abundant macular carotenoids present in the diet and are responsible for the bright colors of many fruits and vegetables. Lutein (L) and zeaxanthin isomers (Zi) differ by location of a single double bond. Zeaxanthin isomers are $\left(3 R, 3^{\prime} R\right)$ zeaxanthin and $\left(3 R, 3^{\prime} S\right)$-zeaxanthin (also called as meso-zeaxanthin). These macular carotenoids are present in the macula of the retina. Humans are unable to synthesize macular carotenoids and hence supplementation of macular carotenoids will meet their requirements. Many commercially available lutein/zeaxanthin preparations extracted 
from the marigold flower (Tagetes erecta L.) are available. Lutein and zeaxanthin are potent antioxidants, and they can filter high-energy blue light. Thus, Xanthophylls may be protective against photoinduced oxidative damage.

Lutein and zeaxanthin isomers are naturally occurring carotenoids available in several different fruits, vegetables, legumes, skin of seafoods, and eggs. ${ }^{3,4}$ Lutein (L) and zeaxanthin isomers $(\mathrm{Zi})$ may inhibit lipid peroxidation and quench singlet oxygen. ${ }^{2}$ Antioxidants in the body and skin protect against ultraviolet (UV) light. Lutein is a major carotenoid present in skin cells. ${ }^{5}$ Furthermore, lutein and zeaxanthin isomers may inhibit the peroxidation of membrane lipids and protect the skin from high-energy sources., ${ }^{2,6}$ As such, consumption of lutein and zeaxanthin isomers may provide benefits to skin, including protection against blue light or high-energy sources causing oxidative damage to skin. Fifty percent of the total skin oxidative burden is generated by visible light. ${ }^{7}$ High doses of infrared radiation were observed to generate highly reactive singlet oxygen and hydroxyl radicals in human skin. ${ }^{8}$ In addition, blue light violet irradiation may cause degradation of cutaneous carotenoids by $13.5 \%$ and $21.2 \%$ directly after irradiation at $50 \mathrm{~J} / \mathrm{cm}^{2}$ and $100 \mathrm{~J} / \mathrm{cm}^{2}$, respectively $(P<0.05)$, that indirectly indicate the amount of generated free radicals, especially reactive oxygen species (ROS), in human skin. ${ }^{9}$

Lutein and zeaxanthin have been shown to protect human lens cells and rat kidney fibroblasts against oxidative damage in vitro. ${ }^{10,11}$ The decrease in antioxidant enzymes in rat kidney fibroblasts exposed to ultraviolet A (UVA) radiation was inhibited with lutein. ${ }^{10}$ Furthermore, cells incubated with lutein significantly decrease oxidative stress metabolites and degradation (ie, malondialdehyde and 4-hydroxyalkenals) induced by ultraviolet B (UVB) irradiation, by $50 \% .{ }^{11} \mathrm{~L} / \mathrm{Zi}$ protection of tissues from oxidative stress was demonstrated in animal studies. ${ }^{12,13}$ Supplementation with lutein and zeaxanthin protected SKh-1 hairless mice from photoaging and photocarcinogenesis ${ }^{13}$ In L/Z-treated mice, increase in survival time, decrease in tumor multiplicity and total tumor volume, and reductions in skin-fold thickness and number of infiltrating mast cells were observed.

González et $\mathrm{al}^{12}$ compared the effects of $0.4 \%$ or $0.04 \%$ lutein- and zeaxanthin-enriched diets with the effects of a standard control diet, which showed a significant decrease in UVB-induced skin inflammation. Furthermore, there was a significant decrease in apoptotic cells and cell proliferation in the lutein- and zeaxanthin-fed mice compared with control mice.

To date, only four clinical studies have reported the effects of supplementation with lutein and zeaxanthin on oxidative damage or skin health. ${ }^{14-17}$ These small studies demonstrated that $\mathrm{L} / \mathrm{Zi}$ supplementation may reduce oxidative stress and improve skin hydration.

This study investigated the efficacy of lutein $(10 \mathrm{mg} / \mathrm{d})$ and zeaxanthin isomers $(2 \mathrm{mg} / \mathrm{d})$ oil suspension softgel capsule in comparison with a placebo in improving skin color, photoprotective activity, and overall skin tone in healthy male and female adults. The study was conducted based on international standards of Good Clinical Practice, ${ }^{18}$ applicable government regulations, as well as institutional research policies and procedures.

\section{Subjects and methods Subjects}

This study is a randomized, double-blind, placebo-controlled trial with a 12-week supplementation period. Fifty subjects were recruited and 25 subjects were randomized to each treatment. Forty-six subjects completed the study. Four subjects dropped due to personal reasons. Adult male and female volunteers were enrolled in this study. After screening, subjects were randomized to placebo or actives [L/Zi] supplementation.

Study population criteria: Subjects were normal healthy people aged 18-45 years, subjects with mild-to-moderate dry skin (determined by the investigator) and Fitzpatrick skin type II-IV scale were included (Table 1). In addition, subjects were nonsmokers, with body mass index of $20-34 \mathrm{~kg} / \mathrm{m}^{2}$, normal values for clinical blood chemistry, hematology, and normal urine values for standard chemistry. Subjects were requested to avoid carotenoid-rich diets including lutein/ zeaxanthin isomer-rich foods and instructed to follow the dietary restriction list provided for 10 days during the study period. Subjects were requested to avoid exposure to highenergy sources including sunbath and requested to complete all clinic visits and to fill the diaries/records.

Subjects were requested avoid cosmetics such as sunscreen and cosmetic procedures, ie, chemical peels, microdermabrasion, and laser treatment on the forearms and face and to use only the bodywash and body cream provided for the entire 12-week study duration and to follow specific instructions related to their use on study visit days. Subjects were instructed to give signed informed consent.

Table I Fitzpatrick scale

\begin{tabular}{lll}
\hline I & Very fair & Always burns, cannot tan \\
II & Fair & Usually burns, sometimes tans \\
III & Medium & Sometimes burns, usually tans \\
IV & Olive & Rarely burns, always tans \\
V & Brown & Rarely burns, tans easily \\
VI & Dark brown & Never burns, always tans \\
\hline
\end{tabular}


Exclusion criteria include subjects who used retin-A or a retinoid, alpha-hydroxy acids, salicylic acid, or vitamin $\mathrm{C}$ for 3 months before enrollment or using any topical medication on their face. Subjects were excluded if they had a history of, or current, disease or condition on the skin found by the investigator dermatologist (eg, atopic skin, acne vulgaris, facial scars, psoriasis, eczema, and other scaly inflammatory diseases); history of, or current, diagnosis of uncontrolled chronic conditions, use of any dietary supplement, over-thecounter, or prescription product with a sign of improving the appearance or condition of the skin (eg, antioxidants, antiaging retinoids, antibiotics, corticosteroids) within 1 month enrollment; and with a history of severe alcohol consumption or drug abuse in the past year (obtained through medical history). Subjects were excluded if they were participating in another intervention, positive pregnancy test in women of childbearing potential, pregnant or breastfeeding or planning on becoming pregnant, and women of childbearing potential not using effective nonhormonal contraception.

\section{Ethical approval}

The study protocol was approved by an independent institutional review board/Ethics Review Committee IntegReview, Austin, TX, USA. The study trial was registered at ISRCTN \#15646478.

\section{Investigational product}

The investigational product, Lutemax ${ }^{\circledR} 2020$ soft gelatin capsules (Actives [L/Zi]: lutein $10 \mathrm{mg}$ and $2 \mathrm{mg}$ zeaxanthin isomers, obtained from the extract of dried flowers of marigold, Tagetes species) supplied by OmniActive Health Technologies Ltd., India. A matched placebo (safflower oil) in size and appearance was used. Subjects were instructed to take one softgel daily with water, after breakfast for 12 weeks.

\section{Methods}

\section{Vital signs and medical history}

Blood pressure, pulse rate, breathing rate, and body temperature were recorded. Medical/cosmetic history and diaries were collected from all the subjects.

\section{Subjective assessments and skin elasticity}

Subjects completed a self-assessment questionnaire to assess overall skin tone (firmness, dryness, radiance and texture, and appearance of pores), facial discoloration, facial lines, and wrinkles based on the clinical evaluations obtained using the 10-point visual analog scale (where $0=$ none, $1-3=$ mild, $4-6=$ moderate, and
$7-9=$ severe). Overall skin health assessments such as skin tone were assessed using a visual analog scale questionnaire. Overall skin tone is defined as overall skin color and a reflection of skin health.

Cutometer $^{\circledR}$ MPA 580 (Courage+ Khazaka electronic $\mathrm{GmbH}$, Germany) was used to measure forearm skin elasticity.

\section{Skin color and photoprotective activity assessments}

Minolta Chromameter CR-400 was used to measure photoprotective activity and skin surface redness 24 hours after exposure of the right forearm to $60 \mathrm{~mJ} / \mathrm{cm}^{2} \mathrm{UVA} / \mathrm{UVB}$ light (280-320 nm) from a $150 \mathrm{~W}$ solar stimulator. Standard procedures and methods were used to determine minimum erythemal dose (MED) for untreated skin before initiation of the study. MED for treated skin was determined during the study period.

Chromametry (Chromameter Minolta CR-200, Ahrensburg, Germany) using three-dimensional color system ( $L$-, $a$-, and $b$-values) was used to measure skin color. Three different measures to indicate skin color were determined. Lightness of skin was measured by $L$-values, sallowness was an indicative of $b$-values (blue/yellow axis), red/ green axis was a measure of $a$-values (red/green axis), and erythema formation to quantify skin responses to highenergy sources. Individual typological angle $\left(\right.$ ITA $\left.^{\circ}\right)$ is an index that determines the skin color or skin pigmentation degree of a subject.

$$
\operatorname{ITA}^{\circ}=\left[\operatorname{Arctan}\left(\left(L^{*}-50\right) / b^{*}\right)\right] \times 180
$$

\section{VISIA-CR ${ }^{\circledR} 2.2$}

The Canfield VISIA-CR ${ }^{\circledR}$ 2.2 Facial Imaging Booth w/Canon 5D Professional Digital body gives photographs of the face during the study. The hardware controlled and images are data-based analyzed using Canfield software. A photoconsent form was provided to the subject for permission to use the photographs.

With regard to the clinical photographs, the only variable during the study was condition of the skin. Therefore, anything extraneous to the skin (jewelry, makeup, clothing, etc) was eliminated from the photographic fields from baseline to the last series of photographs. Lighting, framing, exposure, and reproduction ratios were held constant. At the end of the study, the photographs simulate a time-lapsed movie.

Compliance: Subjects completed compliance records daily to document that the daily doses have, indeed, been consumed and that they consumed according to dosing 
instructions (ie, after the breakfast meal). Compliance was measured by counting the number of unused study products collected during the midpoint and last visits.

Safety: Adverse events information based on subject reports and safety clinical chemistry measures were recorded. Clinical biochemistries such as hematology, hemoglobin, components of complete blood count, blood urea nitrogen, creatinine, liver, and kidney functions were assessed. Specific gravity, $\mathrm{pH}$, protein, glucose, ketones, bilirubin, blood, nitrite, leukocytes, and microscopic urine assessments were analyzed for all participants.

\section{Statistical analysis}

The results were statistically analyzed using methods of descriptive and inference statistics. The intent-to-treat analysis was conducted between the treatment and within groups. The time points were compared using a two-sided paired Student's $t$-test. The pre/post differences were compared among the groups using a two-sided, two-sample Student's $t$-test. $P<0.05$ was determined as statistical significance.

\section{Results}

The baseline characteristics of the subjects are shown in Table 2. The mean age of subjects was $36.1 \pm 5.3$ years, and they had normal healthy body mass index. The skin phototype according to Fitzpatrick's classification was types II-IV. A subset of analysis was conducted for subjects with skin types II and III.

Table 2 Baseline characteristics (mean \pm SD)

\begin{tabular}{lll}
\hline Details & Placebo & Actives \\
\hline Age, years & $37.6 \pm 6.0$ & $36.0 \pm 7.8$ \\
$\mathrm{Sex}, \mathrm{M} / \mathrm{F}$ & $3 / 18$ & $4 / 23$ \\
$\mathrm{BMI}, \mathrm{kg} / \mathrm{m}^{2}$ & $26.05 \pm 3.57$ & $26.83 \pm 3.6$ \\
$\mathrm{SBP}, \mathrm{mmHg}$ & $114 \pm 11.13$ & $1 \mathrm{II} \pm 12.19$ \\
$\mathrm{DBP}, \mathrm{mmHg}$ & $73 \pm 7.93$ & $72 \pm 10.43$ \\
Heart rate (HR), beats per minute & $70 \pm 10.92$ & $67 \pm 10.55$ \\
Respiratory rate, breaths per minute & $16 \pm 1.99$ & $18 \pm 1.87$ \\
Oral temperature, ${ }^{\circ} \mathrm{F}$ & $98.51 \pm 0.43$ & $98.45 \pm 0.55$ \\
\hline
\end{tabular}

Abbreviations: M/F, male/female; BMI, body mass index; SBP, systolic blood pressure; DBP, diastolic blood pressure; SD, standard deviation.

\section{Minimal erythema dose}

An increase in MED was observed in actives over baseline. No significant difference was observed between the placebo and L/Zi groups (Figure 1). The higher the MED, the greater the individual's resistance to the production of erythema.

\section{Chromameter}

Change in skin color was observed, and ITA $^{\circ}$ calculation and visual grading of standardized photographs were taken by a dermatologist. Table 3 shows a significant increase in $L^{*}$ and $\mathrm{ITA}^{\circ}$ after 12 weeks of $\mathrm{L} / \mathrm{Zi}$ supplementation compared to baseline and also shows a highly significant decrease in skin sallowness after $\mathrm{L} / \mathrm{Zi}$ supplementation over baseline. Significant change was observed with the placebo but the difference in the L/Zi group was more significant than placebo. The changes in color were consistent in $\mathrm{L} / \mathrm{Zi}$ supplementation group. Overall an increase in MED, an increase in $L^{*}$, a decrease in $b^{*}$, and an increase in $\mathrm{ITA}^{\circ}$ suggest that $\mathrm{L} / \mathrm{Zi}$ supplementation use may be effective in whitening the skin. The skin-lightening effect of L/Zi may be attributed to its antioxidant activity.

\section{Subjective assessments and skin elasticity}

Subjective assessments are reported in Table 4. Skin tone evenness was significant in $\mathrm{L} / \mathrm{Zi}$ treatment over baseline, and a trend of significance was observed for skin firmness in $\mathrm{L} / \mathrm{Zi}$ treated group. Skin tone clarity was increased, and facial fine lines and wrinkles were increased in placebo. An overall skin

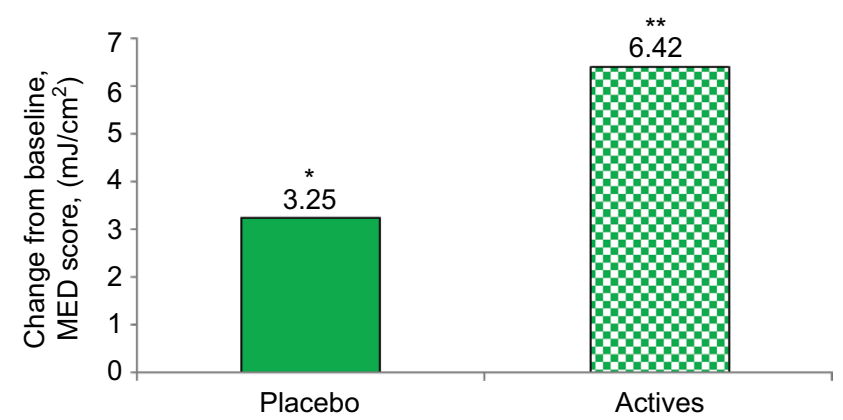

Figure I MED improved after lutein and zeaxanthin isomers $(\mathrm{L} / \mathrm{Zi})$ supplementation. Notes: *Mean significant difference from baseline: placebo: $P<0.0139$ and $* * \mathrm{~L} / \mathrm{Zi}$ (actives): $P<0.0001$.

Abbreviation: MED, minimal erythemal dose.

Table 3 An increase in $L^{*}$, ITA, and decrease in $b^{*}$ observed after L/Zi supplementation indicative of skin lightening

\begin{tabular}{lllllllll}
\hline Area & Placebo & & & \multicolumn{2}{l}{ L/Zi (actives) } \\
\cline { 2 - 3 } & Baseline & Week I2 & Difference from baseline & & Baseline & Week I2 & Difference from baseline \\
\hline$L^{*}$ & 62.02 & 62.59 & $0.57(0.3216)$ & & 62.04 & 63.08 & $1.23^{\mathrm{a}}(0.0094)$ \\
$b^{*}$ & 16.50 & 15.94 & $-0.56^{\mathrm{a}}(0.03)$ & & 16.22 & 15.35 & $-1.05^{\mathrm{a}}(0.0013)$ \\
ITA & 35.91 & 37.79 & $1.88(0.0754)$ & 36.3 & 39.97 & $3.67^{\mathrm{a}}(0.0009)$ \\
\hline
\end{tabular}

Notes: aSignificance over baseline; $P$-value in parenthesis.

Abbreviations: ITA, individual typological angle; $L$, lutein; $\mathrm{Zi}$, zeaxanthin isomers. 
Table 4 Subjective assessments for skin attributes (mean change from baseline)

\begin{tabular}{lll}
\hline Area & Placebo & L/Zi (actives) \\
\hline Facial discoloration & -1.20 & $9.87^{\mathrm{a}}$ \\
Facial lines and wrinkles & 7.75 & 4.87 \\
Overall skin tone $^{\mathrm{b}}$ & -8.20 & 7.04 \\
\hline
\end{tabular}

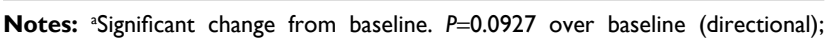
placebo: $P>0.5$. ${ }^{b}$ Significant changes between the treatments.

Abbreviations: $\mathrm{L}$, lutein; $\mathrm{Zi}$, zeaxanthin isomers.

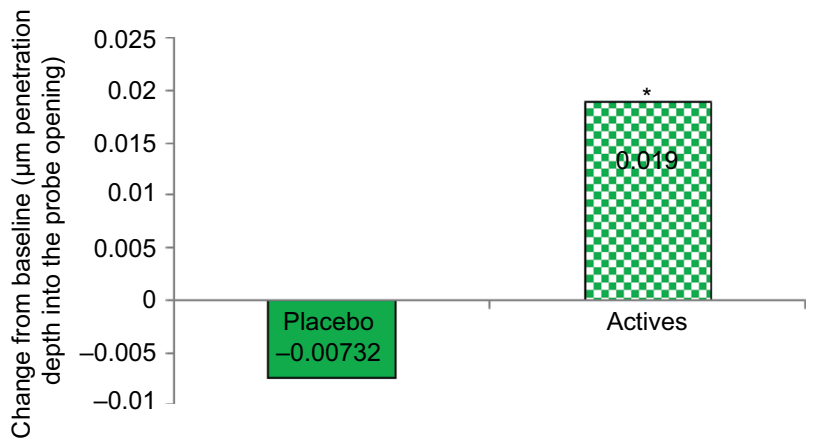

Figure 2 Significant increase in elastic recovery after supplementation with $\mathrm{L} / \mathrm{Zi}$. Note: $* P<0.05$.

Abbreviation: $\mathrm{L} / \mathrm{Zi}$, lutein and zeaxanthin isomers.

tone improvement was observed in $\mathrm{L} / \mathrm{Zi}$ supplementation. An increase in extensibility and faster elastic recovery of the skin (Figure 2) were observed in L/Zi group. Elastic recovery was higher with more firmness of the skin in $\mathrm{L} / \mathrm{Zi}$ treatment.

Safety: no significant adverse events were related to product, and no changes in clinical biochemistries were observed in both groups.

\section{Discussion}

Lutein and zeaxanthin isomers ( $/ \mathrm{Zi})$ have photoprotective action. An increasing MED through antioxidant or anti-inflammatory mechanisms may be due to the melanin photooxidative process. $\mathrm{L} / \mathrm{Zi}$ are carotenoids and capable of quenching ROS such as singlet oxygen and may be effective scavengers of free radicals. ${ }^{19-24}$ In a randomized clinical trial supplementation of $\beta$-carotene $(30 \mathrm{mg} / \mathrm{d})$, retinol/retinyl palmitate (vitamin A, 25,000 IU) for 4 years had no benefit and observed an incidence of lung cancer and on the risk of death from lung cancer, cardiovascular disease in participants. ${ }^{25}$ In another trail, ${ }^{26}$ a combination of $\beta$-carotene $(20 \mathrm{mg} / \mathrm{d})$ and alpha-tocopherol had little or no effect on the incidence of cancer other than lung cancer or no clear effect on total mortality, although more deaths were observed with hemorrhagic stroke. Fewer cases of prostate cancer were diagnosed in alpha-tocopherol $(50 \mathrm{mg} / \mathrm{d})$ group. Total mortality due to lung cancer and ischemic heart disease was observed in $>8 \%$ ( $95 \%$ confidence interval, $1-16$ ). ${ }^{25}$
In 2006, AREDS2 researchers reported a 5-year supplementation study, in which substituting macular carotenoids (10 $\mathrm{mg}$ lutein and $2 \mathrm{mg}$ zeaxanthin) to be a appeared safe and effective alternative to $\beta$-carotene. Subjects reported $18 \%$ reduction in progression to advanced AMD in L/Ztreated group and reduction is higher in lowest dietary intake. In the US, the dietary intake of lutein and zeaxanthin $(\mathrm{L} / \mathrm{Z})$ is typically $<1 \mathrm{mg} / \mathrm{d}$. The study suggests that $\mathrm{L}$ and $\mathrm{Z}$ plus AREDS formula reduced progression to legal blindness. ${ }^{27}$ Overall, 5-year supplementation with $\mathrm{L}$ and $\mathrm{Z}$ supplementation suggests safety and may be a substitute for $\beta$-carotene.

Lipid peroxidation and generation of peroxyl radicals may result due to exposure to high-energy sources. ${ }^{20}$ Lutein and zeaxanthin isomers are thought to play an important role in the filtration of blue light, particularly protection against photooxidative damage. ${ }^{22}$

In the present study, we demonstrated that daily supplementation of $\mathrm{L} / \mathrm{Zi}$ decreases the intensity of erythema induced by UV-light exposure compared to placebo. Other in vitro studies have suggested that lutein and zeaxanthin are more resistant to degradation from oxidative stress in comparison to other carotenoids (ie, $\beta$-carotene and lycopene). ${ }^{23}$

Given their ability to act as potent antioxidants and light filters, lutein and zeaxanthin have been proposed to confer protection against oxidative damage in the skin. Following exposure to UV irradiation, the generation of ROS and the resulting photooxidative damage are manifested as erythema formation (ie, sunburn), which cumulatively can lead to aging of the skin and development of photodermatoses and cancer. $^{28}$

MED increased in L/Zi-treated group, and no erythema was observed. In a recent study, ${ }^{29}$ mild UV irradiation affected significant changes including downregulation of c-SRC and $\beta$-catenin and upregulation of $G$ proteins. There were changes in cytokine gene expression and enhanced antioxidant genes (superoxide dismutase, glutathione peroxidase).

Skin from animals fed diets containing $0.4 \%$ lutein had much less formation of ROS following UV irradiation compared to skin from control mice when tested ex vivo. ${ }^{30}$ Mice consuming lutein plus zeaxanthin had significant reductions in apoptotic keratinocytes compared to controls. ${ }^{12}$ Moreover, mice receiving lutein plus zeaxanthin compared to controls reported protection against photoaging effects of UVB radiation. ${ }^{13}$

Studies have noted the presence of lutein and zeaxanthin in skin, which may reduce oxidative metabolites. ${ }^{30,31}$ People who regularly consume multivitamins reported higher levels 
of carotenoids, including lutein, in skin compared to nonsupplementing people. ${ }^{30,32}$ Lutein and zeaxanthin supplementation/topical application on skin health was reported in a small randomized trial and demonstrated that photoprotective activity was highest in the combined treatment group (oral combined with topical treatment) and skin elasticity unchanged after 8 weeks. In the current study, L/Zi supplementation increased MED after 12 weeks supplementation, and elastic recovery with more firmness was also observed.

Some of the topical skin-lightening products may cause inflammatory conditions and infections, photosensitivity, and hyperpigmentation. $\mathrm{L} / \mathrm{Zi}$ was studied for more than 3 decades in vision health conditions and $>10,000$ people were included in the vision studies at a dose range of 6-40 mg L, up to $8 \mathrm{mg} R R$-zeaxanthin and $17 \mathrm{mg} R S$ (meso)-zeaxanthin over 5 years. No adverse events were reported, nor changes in clinical biochemistries were observed.

Carotenoids possess anti-inflammatory properties. ${ }^{33}$ Other carotenoids such as $\beta$-carotene and lycopene exhibit antioxidant activity and affect gene signaling and expression at the molecular level. They protect the skin against solar erythema may be by increasing basal defense against high-energy light-mediated damage ${ }^{34}$ causing dark acne scars, freckles, dark underarms, and age spots. ${ }^{35} \beta$-Carotene or lycopene may exhibit absorption at wavelengths of UVB and UVA range, respectively, and may protect against photodamage. $\mathrm{L} / \mathrm{Z}$ are not converted to vitamin $\mathrm{A}$ and thus are unlikely to exert the adverse effects associated with hypervitaminosis $\mathrm{A}^{36,37}$

In a clinically diagnosed study, 31 adults ( 26 females and five males) with melasma and with high-grade pigmentation improved to a lower grade of pigmentation with topical treatment with $\beta$-carotene, and some cases recovered completely. Only two participants had mild erythema and local irritation. ${ }^{39}$ In another study, the intensity of redness of the skin 24 hours after irradiation was observed in $\beta$-carotene-treated group $(24 \mathrm{mg} / \mathrm{d})$ and $8 \mathrm{mg} / \mathrm{d}$ carotenoid mix-treated group $\left(\beta\right.$-carotene, lutein, and lycopene). ${ }^{40}$

The pigmentation is due to overproduction of melanin by the pigment cells, melanocytes, which is taken up by the keratinocytes (epidermal melanosis) and/or deposited in the dermis (dermal melanosis and melanophages). Topical application of $\beta$-carotene lotion appears to be effective and safe in the treatment of melasma. In an isolated case study, a 69-year-old female with antecedent of breast cancer and recent transitory neurological symptoms ${ }^{40}$ reported yellowto-orange skin pigmentation, more conspicuous on her palms and soles, while discoloration changes were absent in the eye and oral mucous membranes. The skin discoloration improved in $\sim 2$ months after correction of the inadequate diet. $^{40}$

Carotenemia and lycopenemia are more accentuated on the palms and soles because the stratum corneum is thicker in these regions ${ }^{41}$ Discoloration of palms and soles is consequence of pigment deposit due to slow conversion of carotenoids to vitamin A. ${ }^{42-45}$ In another case, a 68-yearold Caucasian female was presented with red-orange tinged skin of the palms and soles. Her diet includes $1 \mathrm{~kg}$ of kaki fruit daily. This condition disappeared after changes in her dietary habits. ${ }^{43}$ Another interesting case of carotenemia was described in an 66-year-old female secondary to increased ingestion of oral supplements of carotene. ${ }^{44}$ Based on these isolated case reports in old females, it is important to explore carotenoid intake, absorption, and effects on skin in aging.

Based on National Health Surveys, US adults consume vegetables $(37.7 \%)$ and fruits $(22.6 \%)$ less than one time a day. ${ }^{38,46}$ Hammond et $\mathrm{a}^{47}$ reported that people differ in their carotenoid absorption, especially from food. Further long-term studies need to explore on dietary lutein and $\mathrm{Zi}$ intakes and skin health in aging. The antioxidant properties of $\mathrm{L} / \mathrm{Zi}$ are reported in several studies and reducing free radicals. The skin-lightening effect of L/Zi (Figure 3) may be due to its property of filtering out high-energy blue light rays present in sunlight and indoor lighting, and as a UV absorber/filter, it may also enhance tyrosinase inhibition and certainly increases antioxidant capacity. Skin color is a result of the melanin types (pheomelanin and eumelanin) as well as where the melanin is concentrated in the skin. By reducing the inflammation and blocking the free radicals, L/ $\mathrm{Zi}$ reduces the formation of both melanin types. The reduction in eumelanin leads to an increase in the $L^{*}$ value, while the reduction in the pheomelanin leads to a decrease in the $b^{*}$ value. This in turn will lead to an increase in the $\operatorname{ITA}^{\circ}$, ie, a lightening of the overall skin tone. Because the $\mathrm{L} / \mathrm{Zi}$ is taken orally, its concentration in the skin starts with the dermis then the epidermis reducing the depth of pigmentation. Few studies are ongoing to explore its mechanism of action on skin lightening and pigmentation. Current findings are from a 3-month study, and further long-term supplementation studies in different population are warranted.

\section{Conclusion}

Our study indicates that L/Zi (Lutemax $\left.{ }^{\circledR} 2020\right)$ supplementation can promote skin lightening and improve skin health conditions. The mechanism by which supplementation effectively whitens the skin was due to its antioxidant properties 


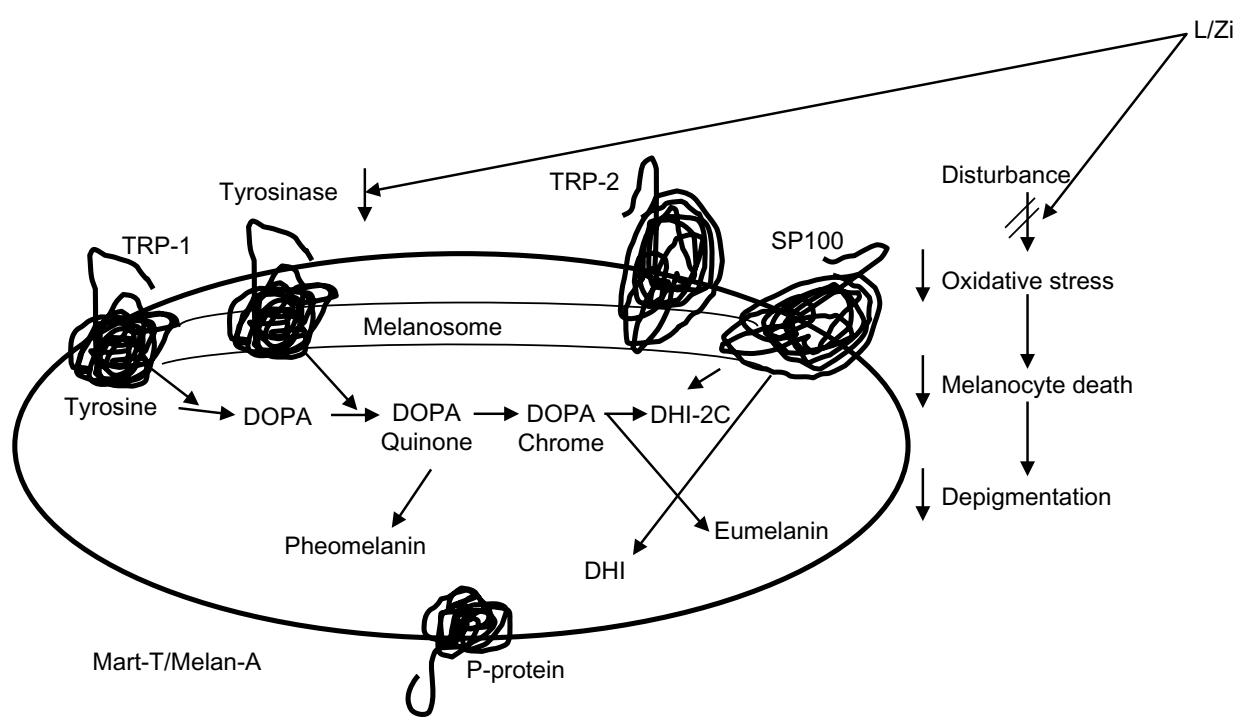

Figure 3 Potential mechanism of action of L/Zi.

Abbreviations: $\mathrm{L} / \mathrm{Zi}$, lutein and zeaxanthin isomers; $\mathrm{DHI}$, dihydroxyindole; P-protein, pink-eyed dilution protein; TRP, tyrosinase related protein.

and photoprotective activity. More research is required to understand the biological effects and photoprotective activity of $\mathrm{L} / \mathrm{Zi}$ supplementation.

\section{Acknowledgments}

The authors thank TKL Research Inc. and participants for their valuable time. Abstract accepted and presented at the American Society for Nutrition's (ASN) Advances and Controversies in Clinical Nutrition Conference, CA 2015, USA.

\section{Disclosure}

VJ and JD are employees of OmniActive Health Technologies Inc. The authors report no other conflicts of interest in this work.

\section{References}

1. Valko M, Leibfritz D, Moncol J, Cronin MT, Mazur M, Telser J. Free radicals and antioxidants in normal physiological functions and human disease. Int J Biochem Cell Biol. 2007;39:44-84.

2. Roberts RL, Green J, Lewis B. Lutein and zeaxanthin in eye and skin health. Clin Dermatol. 2009;27(2):195-201.

3. Sommerburg O, Keunen JE, Bird AC, van Kuijk FJ. Fruits and vegetables that are sources for lutein and zeaxanthin: the macular pigment in human eyes. Br J Ophthalmol. 1998;82(8):907-910.

4. Perry A, Rasmussen H, Johnson EJ. Xanthophyll (lutein, zeaxanthin) content in fruits, vegetables and corn and egg products. J Food Comp Anal. 2009;22:9-15.

5. Wingerath T, Sies H, Stahl W. Xanthophyll esters in human skin. Arch Biochem Biophys. 1998;355(2):271-274.

6. McNulty HP, Byun J, Lockwood SF, Jacob RF, Mason RP. Differential effects of carotenoids on lipid peroxidation due to membrane interactions: X-ray diffraction analysis. Biochim Biophys Acta. 2007;1768(1):167-174.

7. Zastrow L, Groth N, Klein F, et al. The missing link - light-induced $(280-1,600 \mathrm{~nm})$ free radical formation in human skin. Skin Pharmacol Physiol. 2009;22(1):31-44.
8. Akhalaya MY, Maksimov GV, Rubin AB, Lademann J, Darvin ME Molecular action mechanisms of solar infrared radiation and heat on human skin. Ageing Res Rev. 2014;16:1-11.

9. Vandersee S, Beyer M, Lademann J, Darvin ME. Blue-violet light irradiation dose dependently decreases carotenoids in human skin, which indicates the generation of free radicals. Oxid Med Cell Longev. 2015;2015:579675.

10. O'Connor I, O'Brien N. Modulation of UVA light-induced oxidative stress by beta-carotene, lutein and astaxanthin in cultured fibroblasts. J Dermatol Sci. 1998;16(3):226-230.

11. Chitchumroonchokchai C, Bomser JA, Glamm JE, Failla ML. Xanthophylls and alpha-tocopherol decrease UVB-induced lipid peroxidation and stress signaling in human lens epithelial cells. $J$ Nutr. 2004;134(12):3225-3232.

12. González S, Astner S, An W, Goukassian D, Pathak MA. Dietary lutein/ zeaxanthin decreases ultraviolet B-induced epidermal hyperproliferation and acute inflammation in hairless mice. $J$ Invest Dermatol. 2003;121(2):399-405.

13. Astner S, Wu A, Chen J, et al. Dietary lutein/zeaxanthin partially reduces photoaging and photocarcinogenesis in chronically UVB-irradiated Skh-1 hairless mice. Skin Pharmacol Physiol. 2007;20(6):283-291.

14. Collins AR, Olmedilla B, Southon S, Granado F, Duthie SJ. Serum carotenoids and oxidative DNA damage in human lymphocytes. Carcinogenesis. 1998;19(12):2159-2162.

15. Hininger IA, Meyer-Wenger A, Moser U, et al. No significant effects of lutein, lycopene or $\beta$-carotene supplementation on biological markers of oxidative stress and LDL oxidizability in healthy adult subjects. $J \mathrm{Am}$ Coll Nutr. 2001;20:232-238.

16. Zhao X, Aldini G, Johnson EJ, et al. Modification of lymphocyte DNA damage by carotenoid supplementation in postmenopausal. Am J Clin Nutr. 2006;83:163-169.

17. Palombo P, Fabrizi G, Ruocco V, et al. Beneficial long-term effects of combined oral/topical antioxidant treatment with the carotenoids lutein and zeaxanthin on human skin: a double-blind, placebo-controlled study. Skin Pharmacol Physiol. 2007;20(4):199-210.

18. ICH Topic E6, 1996 [webpage on the Internet]. Guidance for Industry E6 Good Clinical Practice: Consolidated Guidance. Available from: http://www.fda.gov/downloads/Drugs/GuidanceComplianceRegulatoryInformation/Guidances/ucm073122.pdf. Accessed January 14, 2016.

19. Stahl W, Sies H. Carotenoids and protection against solar UV radiation. Skin Pharmacol Appl Skin Physiol. 2002;15(5):291-296. 
20. Rahman K. Studies on free radicals, antioxidants, and co-factors. Clin Interv Aging. 2007;2(2):219-236.

21. Stahl W, Sies H. Antioxidant activity of carotenoids. Mol Aspects Med. 2003;24(6):345-351.

22. Sies H, Stahl W. Non-nutritive bioactive constituents of plants: lycopene, lutein and zeaxanthin. Int J Vitam Nutr Res. 2003;73(2):95-100.

23. Loane E, Kelliher C, Beatty S, Nolan JM. The rationale and evidence base for a protective role of macular pigment in age-related maculopathy. Br J Ophthalmol. 2008;92(9):1163-1168.

24. Siems WG, Sommerburg O, Van Kuijk FJ. Lycopene and $\beta$-carotene decompose more rapidly than lutein and zeaxanthin upon exposure to various pro-oxidants in vitro. Biofactors. 1999;10:105-113.

25. Omenn GS, Goodman GE, Thornquist MD, et al. Effects of a combination of beta carotene and vitamin A on lung cancer and cardiovascular disease. $N$ Engl J Med. 1996;334(18):1150-1155.

26. The Alpha-Tocopherol, Beta Carotene Cancer Prevention Study Group. "The Alpha-Tocopherol Beta Carotene Cancer Prevention Study Group. The effect of vitamin E and beta carotene on the incidence of lung cancer and other cancers in male smokers". N Engl J Med. 1994;330(15):1029-1035.

27. The Age-Related Eye Disease Study 2 (AREDS2) Research Group. Lutein + zeaxanthin and omega-3 fatty acids for age-related macular degeneration the age-related eye disease study 2 (AREDS2) randomized clinical trial. JAMA. 2013;309(19):2005-2015.

28. Stahl W, Sies H. Bioactivity and protective effects of natural carotenoids. Biochim Biophys Acta. 2005;1740(2):101-107.

29. Juturu V, Deshpande J, Ghanam K, Doyle L. Soluble lutein inhibits cholinesterase and reduces ultraviolet radiation induced inflammation and immunosuppression: in vitro model. Eur J Ophthalmol. 2015;25:e63,MC017.

30. Lee EH, Faulhaber D, Hanson KM, et al. Dietary lutein reduces ultraviolet radiation-induced inflammation and immunosuppression. J Invest Dermatol. 2004;122(2):510-517.

31. Peng YM, Peng YS, Lin Y, Moon T, Roe DJ, Ritenbaugh C. Concentrations and plasma-tissue-diet relationships of carotenoids, retinoids, and tocopherols in humans. Nutr Cancer. 1995;23(3):233-246.

32. Wingerath T, Stahl W, Sies H. $\beta$-cryptoxanthin selectively increases in human chylomicrons upon ingestion of tangerine concentrate rich in $\beta$-cryptoxanthin esters. Arch Biochem Biophys. 1995;324:385-390.

33. Alves-Rodrigues A, Shao A. The science behind lutein. Toxicol Lett. 2004;83:150-157.
34. Fuller B, Smith D, Howerton A, Kern D. Anti-inflammatory effects of CoQ10 and colorless carotenoids. J Cosmet Dermatol. 2006;5(1):30-38.

35. Sies H, Stahl W. Nutritional protection against skin damage from sunlight. Annu Rev Nutr. 2004;24:173-200.

36. Von Oppen-Bezalel L. Round-up: colorless carotenoids may protect skin against inflammation and UV radiation. Fragrance J. 2006;34: $48-53$.

37. Granado F, Olmedilla B, Blanco I. Nutritional and clinical relevance of lutein in human health. Br J Nutr. 2003;90(3):487-502.

38. IOM [webpage on the Internet]. Vitamin A. Dietary Reference Intakes: For Vitamin A, Vitamin K, Arsenic, Boron, Chromium, Copper, Iodine, Iron, Manganese, Molybdenum, Nickel, Silicon, Vanadiam, and Zinc. National Academy of Sciences, Panel on Micronutrients, Food and Nutrition Board, Institute of Medicine (IOM). Washington, DC: National Academy Press (NAP); 2001:82-161. Available from: http:// www.nap.edu/openbook.php?isbn=0309072794. Accessed January 24, 2016.

39. Kar HK. Efficacy of beta-carotene topical application in melasma: an open clinical trial. Indian J Dermatol Venereol Leprol. 2002;68: 320-322.

40. Heinrich U, Gärtner C, Wiebusch M, et al. Supplementation with betacarotene or a similar amount of mixed carotenoids protects humans from UV-induced erythema. J Nutr. 2003;133(1):98-101.

41. Santos VM, Camilo AG, Souza LA, Souza DW, Marinho CS, Monteiro LM. A woman with treated breast cancer, recent neurological symptoms and xanthoderma. Acta Med Iran. 2013;51(3):195-198.

42. Hess AF, Myers VC. Carotinemia: a new clinical picture. JAMA. 1919; 73:1743-1745.

43. Caroselli C, Bruno G, Manara F. A rare cutaneous case of carotenosis cutis: lycopenaemia. Ann Nutr Metab. 2007;51(6):571-573.

44. Constanza DJ. Carotenemia associated with papaya ingestion. Calif Med. 1968;109:319-320.

45. Takita Y, Ichimiya M, Hamamoto Y, Muto M. A case of carotenemia associated with ingestion of nutrient supplements. J Dermatol. 2006; 33(2):132-134

46. State of Obesity [webpage on the Internet]. State Rates of Fruit and Vegetable Consumption. Available from: http://stateofobesity.org/lists/ lowest-rates-fruits-vegetables. Accessed June 10, 2016.

47. Hammond BR Jr, Wooten BR, Snodderly DM. Preservation of visual sensitivity of older subjects: association with macular pigment density. Invest Ophthalmol Vis Sci. 1998;39(2):397-406.
Clinical, Cosmetic and Investigational Dermatology

\section{Publish your work in this journal}

Clinical, Cosmetic and Investigational Dermatology is an international, peer-reviewed, open access, online journal that focuses on the latest clinical and experimental research in all aspects of skin disease and cosmetic interventions. This journal is included on PubMed. The manuscript management system is completely online and includes a very quick and fair peer-review system, which is all easy to use. Visit http://www.dovepress.com/testimonials.php to read real quotes from published authors 